\title{
Mathematical Model of Washing OF Filtration CaKe
}

\author{
Dagmar Janacova, Pavel Mokrejs, Vladislav Sviatskii, \\ Vladimir Vasek, Ondrej Liska \& Karel Kolomaznik
}
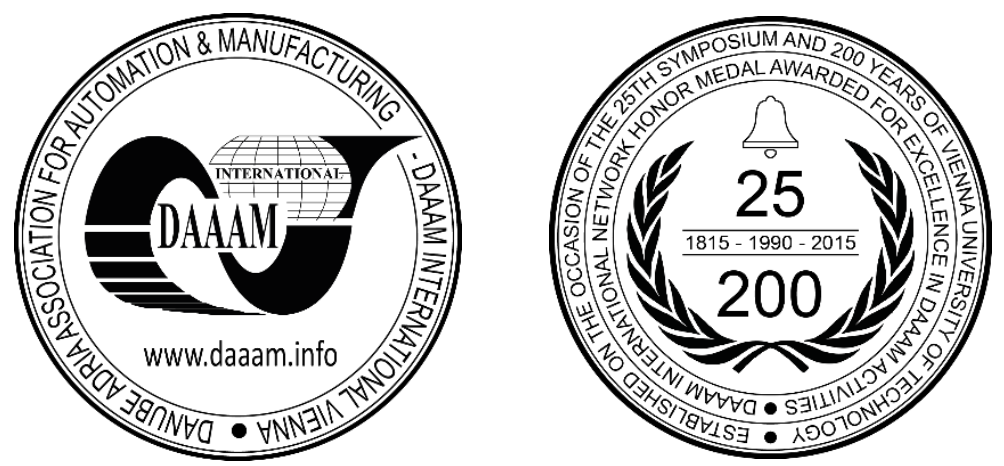

This Publication has to be referred as: Janacova, D[agmar]; Mokrejs, P[avel]; Sviatskii, V[ladislav]; Vasek, V[ladimir]; Liska, O[ndrej] \& Kolomaznik, K[arel] (2017). Mathematical Model of Washing of Filtration Cake, Proceedings of the 28th DAAAM International Symposium, pp.0063-0069, B. Katalinic (Ed.), Published by DAAAM International, ISBN 978-3-902734-11-2, ISSN 1726-9679, Vienna, Austria

DOI: $10.2507 / 28$ th.daaam.proceedings.008

\begin{abstract}
The issue of this article is one stage washing of reaction blend after enzyme hydrolysis under which we are able to recycle almost all contained chromium in solid leather waste. During hydrolysis we gain protein hydrolysate as a filtrate that is appropriate substance for use. On the basis of equation for streaming of liquids through layer of substance we determined optimal pressure differential for filtering and washing of reaction mix and we applied mathematical description valid for filtering and one stage washing and on the basis of this models we able to optimize washing process that is add to filtering and which aim is to reduce content of protein hydrolysate in filter cake.
\end{abstract}

Keywords: filtration process; one stage washing; optimization; filtration cake; protein hydrolysate

\section{Introduction}

In leather industry are created more than five thousand tone chrome tanning waste per year and we can suppose that its amount is going to grow up. The waste is removed to waste dump very often. There chromium poses a threat to ground water because it can escape there. Chromium can be oxidized to hexavalent chromium, its compounds are carcinogenic. It is more than evident that ecological treatment of chrome tanning parings is urgent. Many methods of gaining chromium from chrome tanning parings were conceived.

As the most convenient way is to deal with the waste by enzymatic hydrolysis [1] and during this we are able to recycle almost all used chromium. During hydrolysis we obtain protein hydrolysate as a filtrate. To reduce of the protein hydrolysate content we included washing of the filter cake. Enzyme hydrolysis is environmentally friendly. During this process we fully uses chromium cake and high-quality protein hydrolysate for wide using.

\section{Washing of filter cake}

The product of filter process is filter cake which contains residual amount of filtrate and other substances that are adverse. Washing is the process during it we want to remove a maximum of this substance. During optimization of washing process is important to know whether the washing component belongs to solid phase or not. We must establish sorption isotherm. Common sorption isotherm is depicted in the picture 1. 


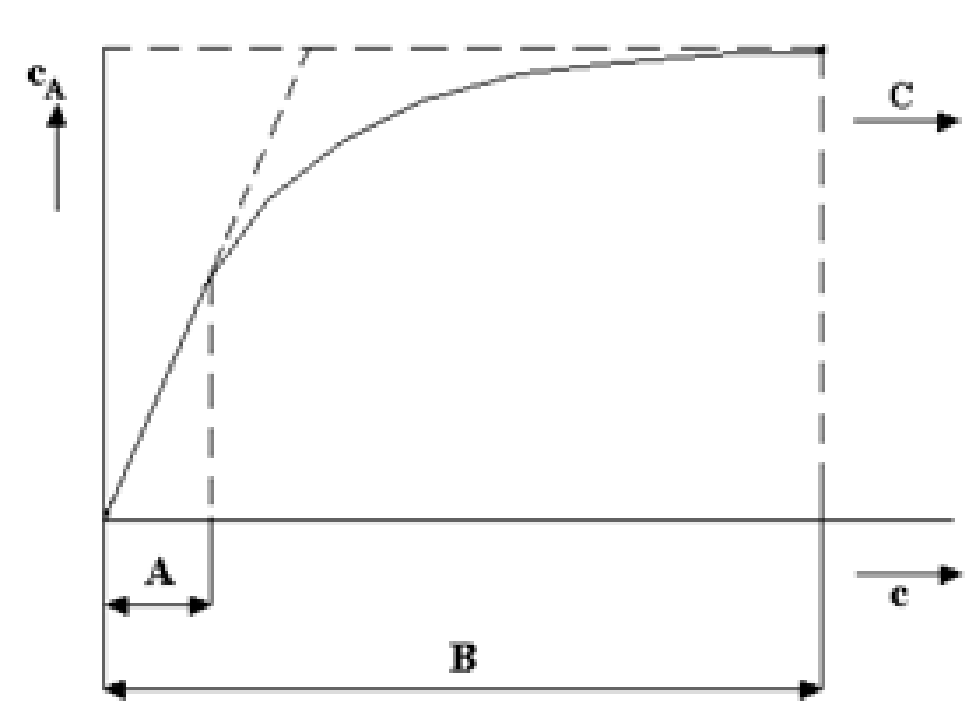

Fig. 1. Langmuir's sorption isotherm

Essential for other process of rationalizing washing process is finding in which part of sorption isotherm we can find the condition of washing substance. According to the picture 1 is the condition " $\mathrm{C}$ " or " $\mathrm{B}$ ". Around "C" is washing substance free. Around " $\mathrm{B}$ " is washing substance connected to solid phase. In this area we can introduce zone " $\mathrm{A}$ " in which is sorption addiction linear [2].

We divide the washing process in two basic categories:

- Washing of untied constituent: washing liquid is usually water.

- Washing of tied constituent: washing liquid is substance in which the tied constituent melts (e.g. washing MgO diluted by solution of sulphuric acid.)

According to technical process we distinguish bath washing. Success rate when is from the cake removed washout substance is the dependence of washing process level $y$ on soaking number $\mathrm{Na}$ [8]:

$$
y=\frac{c_{0} V_{0}}{c_{p} V}=C_{0} \cdot N a
$$

where: $y$ is ratio of removed part of the substance to its whole amount that was in the cake before washing, The value is in interval $0-1, N a$ is ratio of washing liquid volume to solid phase volume, this characterizes usage of washing liquid, $c_{o}$ is concentration of the scrubbed components in the bath, $c_{p}$ is the initial concentration of the scrubbed components in the solid phase (filtration cake), $C_{o}$ is dimensionless concentration of the scrubbed components in the bath.

\section{Mathematic model of filter cake washing}

During this way of washing is filter cake removed from filter apparatus and mixed with such amount of washing liquid to get lower then critical concentration of washing substance. This solution is then filtrated.

Special case of bath washing is decanting washing [5, 7]. During bath washing is the whole amount of washing liquid is used/consumed during one process/operation. Decanting washing means that we use washing liquid in several operations. Bath washing is made several time with lower capacity of washing liquid so long when the figure of concentration of washing constituent is lower than critical figure.

This method is used in case when we wash from cake constituents tied and untied because every type of constituents is washed by different washing liquid [1,9]. Mathematical model is based on equation which describes one-dimensional concentration field of washing constituent in solid phase.

$$
D \frac{d^{2} c}{d x^{2}}=\frac{d c}{d t}(x, t) \quad t>0, \quad 0 \leq x \leq b
$$

and from conditions for this equation: Concentration field in solid phase is symmetrical: 


$$
\frac{d c}{d x}(0, t)=0
$$

Bath is perfectly mixed:

$$
c(b, t)=\varepsilon \cdot c_{0}(t)
$$

The speed of substance of washing constituent on the surface of solid phase is equal to accumulation of this substance in the bath:

$$
-D S \frac{d c}{d x}(b, t)=V_{0} \frac{d c_{0}}{d t}(t)
$$

At the beginning of washing is constant difference of concentration in filter cake:

$$
c(x, 0)=c_{p}
$$

In washing liquid is zero concentration of washing constituent:

$$
c_{0}(0)=0
$$

For general expression we introduce dimensionless quantities:

$$
C=\frac{c}{c_{p}}, \quad C_{0}=\frac{c_{0}}{c_{p}}, \quad F_{0}=\frac{D t}{b^{2}}, \quad X=\frac{x}{b}, \quad N a=\frac{V_{0}}{V}
$$

where: $V$ is je capacity of solid phase.

The result of equation (2) under the conditions (3-7) we accomplished by Laplace transformation [2, 8] and then we get: Dimensionless concentration field in solid phase:

$$
C\left(X, F_{0}\right)=\frac{\varepsilon}{N a+\varepsilon}-2 N a \sum_{n=1}^{\infty} \frac{\cos \left(X q_{n}\right) \cdot e^{-F_{0} q_{n}^{2}}}{\cos \left(q_{n}\right)[N a+\varepsilon]-q_{n} N a \cdot \sin \left(q_{n}\right)}
$$

Time course of concentration of washing constituent in filtrate

$$
C_{0}\left(F_{0}\right)=\frac{1}{N a+\varepsilon}-\frac{2 N a}{\varepsilon} \sum_{n=1}^{\infty} \frac{e^{-F_{0} q_{n}{ }^{2}}}{\varepsilon+N a+\frac{N a^{2} q_{n}{ }^{2}}{\varepsilon}}
$$

Degree of washing $y$ we determined wih using of equation (1) $[3,7]$.

\section{Filter and wash apparatus}

Filter apparatus where I do all my measurements is formed for heated filter funnel and filter receptacle. Vacuum pump is connected to filter receptacle that enables creation of under pressure behind filter divider.

Converters for capacity sensor of water-level, resistance thermometer Pt100 and pressure sensor are together with regulator connected to temperature sensor situated in converter and regulatory cabinet.

Connection of regulatory and converter cabinet to computer enables well arranged monitoring of filter process and archiving of measured data [3, 4]. 


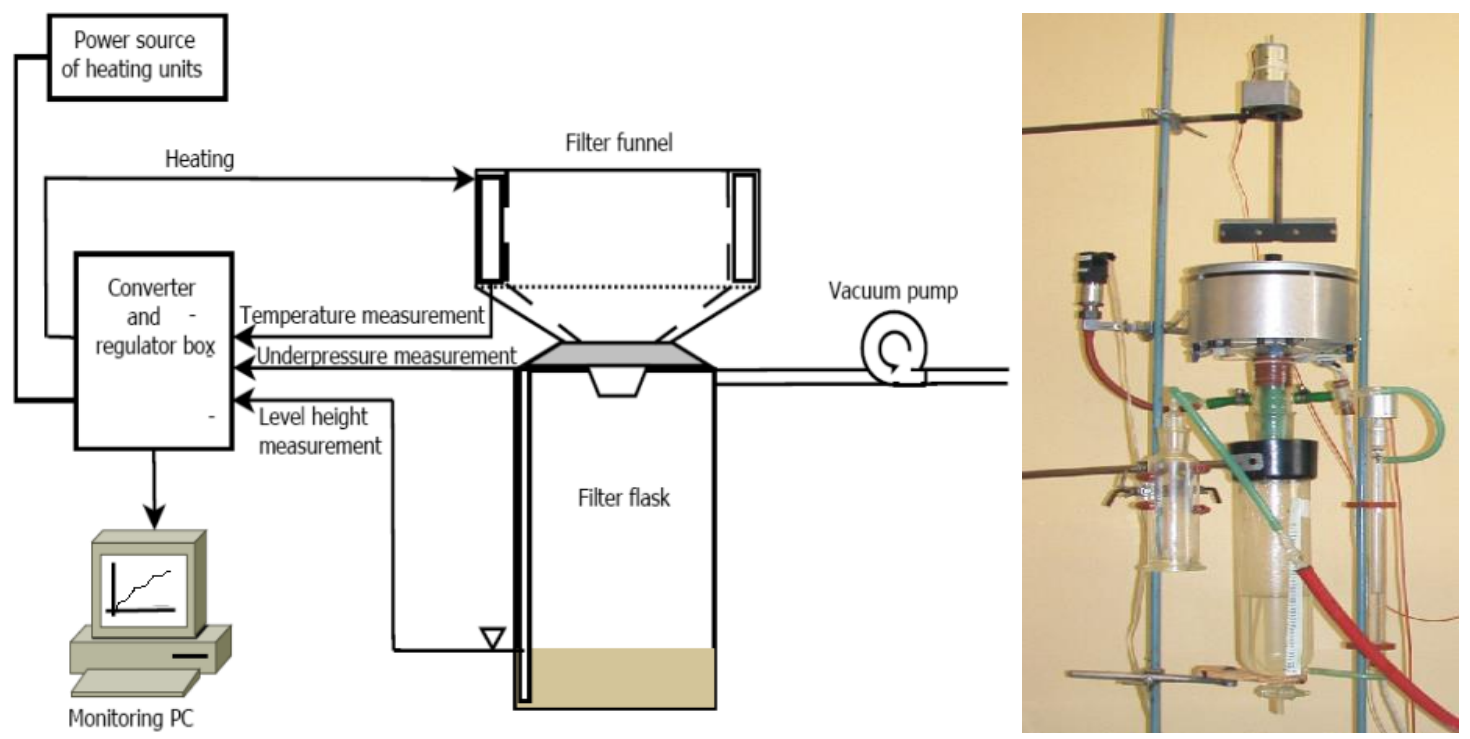

Fig. 2. Filter apparatus [3]

\section{Experimental part of washing}

Filtration cake, which was created from filtration of chromium sludge, was washed. This washing was composed of two phases:

1. Washing of the cake by water in the purpose of removing residual proteins.

2. The cake that was washed was poured by distilled water and was carried out the modification of it $\mathrm{pH}$ by sulphuric acid. This sludge was put to filter funnel and filtered during pouring of distilled water. The aim was to remove residual magnesium oxide from filter cake. From particular filtered cakes and filtrates we removed samples for later analysis which was done in work $[1,5]$.

\section{Experiment No.1:}

The cake was situated in heated filter funnel where was constantly poured distilled water. During stirring the cake was firstly washed by water, then the $\mathrm{pH}$ was changed to 6 by sulphuric acid and then again washed by water. Attributes of entering cake (FK1), cake after washing by water (FK2) and final cake after washing with changed pH (FK3) are depicted in Table 1.

\begin{tabular}{|c|c|c|c|c|c|c|c|c|}
\hline Sample & & $\begin{array}{c}\text { Weight } \\
\text { m }\end{array}$ & Dry part & Ash & $\begin{array}{c}\text { Content } \\
\text { of C }\end{array}$ & $\begin{array}{c}\text { Content } \\
\text { of N }\end{array}$ & $\begin{array}{c}\text { Content } \\
\text { of Cr }\end{array}$ & $\begin{array}{c}\text { Content } \\
\text { of Mg }\end{array}$ \\
\hline FK 1 & {$[\% /$ dry $]$} & - & 18,31 & 28,37 & 29,74 & 10,04 & 5,11 & 5,05 \\
\hline & {$[\mathrm{g}]$} & & & & & & & \\
\hline FK 2 & {$[\% /$ dry $]$} & - & 12,37 & 41,63 & 21,2 & & 9,87 & 8,84 \\
\hline & {$[\mathrm{g}]$} & 840 & 103,91 & 43,26 & 22,03 & & 10,25 & 9,18 \\
\hline FK3 & {$[\% /$ dry } & - & 17,1 & 34,77 & 24,47 & 8,14 & 13,2 & 3,63 \\
\hline & {$[\mathrm{g}]$} & 450 & 76,95 & 26,75 & 18,83 & 6,26 & 10,15 & 2,79 \\
\hline
\end{tabular}

Table 1. Attributes of filter cake No.1

Entering cake FK1 was not weighted therefore it is not able exactly balanced washing of particular parts. (its weight was approximately same as during following attempt: around 1000 - $1150 \mathrm{~g}$ )

$200 \mathrm{ml}$ samples of filtration were taken. After taking first 10 samples during washing by water, the filter cake was removed to beaker, it was weighted, poured by distilled water, and then the change of $\mathrm{pH}$ to 6 by sulphuric acid was carried out (dilute 1:10). Sludge was again removed to filter funnel and distilled water was poured. 10 samples of $200 \mathrm{ml}$ filtration were taken.

Filter funnel was heated to the temperature $55^{\circ} \mathrm{C}$ during washing by water, the temperature of the cake was not measured. When water started to flow in the cake, some amount of water flow in to sampling receptacle therefore there is lower concentration of washed substances in the first sampling filtrate. We stirred the cake because otherwise the cake 
started to crack and started to separate from walls of filter funnel. During the second part of washing, when diluted sulhpuric acid was added to the cake, the filter funnel was not heated.

Equivalent amount of sulphuric acid was not added to the cake so therefore an amount of magnesium was still in the cake. We found out appropriate conditions during this experiment (sampling, regulation of flow and temperature). Experiences were used during following experiment.

\subsection{Experiment No.2:}

During second experiment samples of filtrate cumulated with the amount of 500ml and we took 6 in each period of experiment. The process was the same as during previous case. The temperature of cake in filter funnel was $40^{\circ} \mathrm{C}$ the same as during washing by water and washing after changing $\mathrm{pH}$. Characteristic of filter cake is described in Table 2

\begin{tabular}{|c|c|c|c|c|c|c|c|c|}
\hline Sample & & $\begin{array}{c}\text { Weight } \\
\text { m }\end{array}$ & Dry part & Ash & $\begin{array}{c}\text { Content } \\
\text { of C }\end{array}$ & $\begin{array}{c}\text { Content } \\
\text { of N }\end{array}$ & $\begin{array}{c}\text { Content } \\
\text { of Cr }\end{array}$ & $\begin{array}{c}\text { Content } \\
\text { of } \mathbf{~ M g}\end{array}$ \\
\hline FK 1 & {$[\% /$ dry $]$} & - & 19,4 & 26,52 & 29,64 & 9,58 & 5,45 & 6,02 \\
\hline & {$[\mathrm{g}]$} & 970 & 188,18 & 49,91 & 55,77 & 18,03 & 10,25 & 11,32 \\
\hline FK 2 & {$[\% /$ dry $]$} & - & 15,69 & 28,37 & 27,95 & - & 7,84 & 7,24 \\
\hline & {$[\mathrm{g}]$} & 810 & 127,09 & 36,05 & 37,72 & - & 9,96 & 10,3 \\
\hline FK3 & {$[\% /$ dry } & - & 17,86 & 19,65 & 32,94 & 13,99 & 8,86 & 1,38 \\
\hline & {$[\mathrm{g}]$} & 585 & 104,48 & 20,53 & 36,87 & 14,62 & 9,26 & 2,39 \\
\hline
\end{tabular}

Table 2. Attributes of filter cake No.2

\subsection{Evaluation of measured data}

For evaluation of process for washing the filter cake we used data from experiment No.2 because during the first try the entering cake was not weighted. Therefore we could not precisely evaluate it. The filter cake was weighted only at the beginning and in the end of the process therefore figures for particular parts of the process are not measured. We used average figures. Inaccuracy is not great.

The ratio of filtration volume to solid phase volume we got the figure. The ratio of washing substances to its original amount we defined a degree of washing $\mathrm{y}$. In each chart we have graph dependence $\mathrm{y}$ on $\mathrm{Na}$ (dependence washing quality on output of washing liquid).

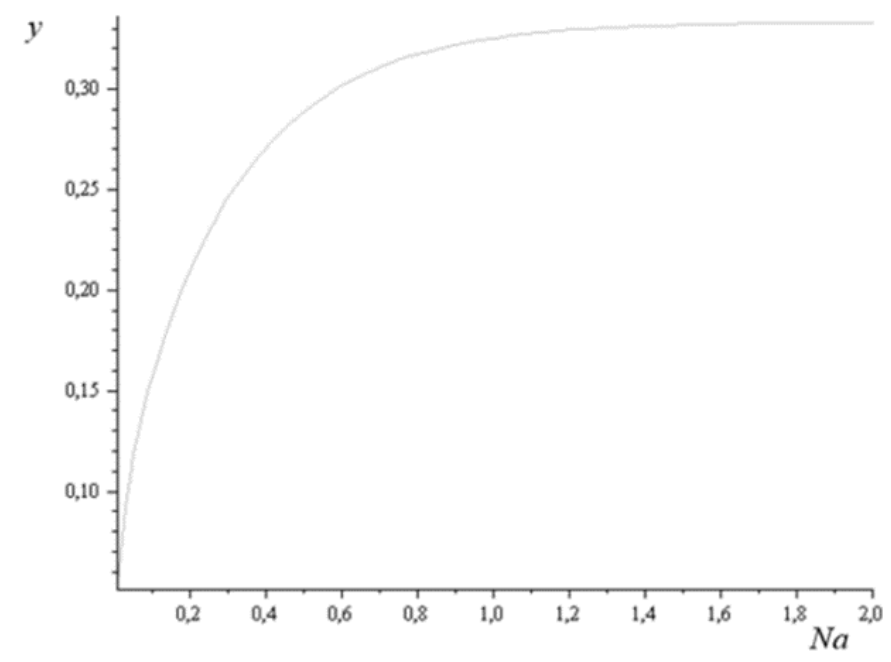

Fig. 3. Dependence y on $\mathrm{Na}$ during washing of protein by water.

\section{Optimization of filtration cake washing}

For washing required amount of undesired substance from filter cake, it is necessary particular amount of washing liquid and energy. In this case it was energy for heating the filter funnel. To have the lowest cost for washing the filter cake, we tried to find minimal volume of washing liquid, that will be sufficient for washing required amount of given substance. The amount of washing substance is characterized by washing level $y[3,6]$. When we want to find out minimum volume we chose appropriate soaking numbers during which we get required degree of washing and then we 
get optimal volume. The volume which is equal to equation minimum is optimum volume and total costs are optimal costs needed for washing required amount of undesirable substance [10].

To wash certain amount of undesirable substance from filter cake, it is necessary a certain amount of washing liquid and also a certain amount of energy. In our case it was the energy for heating the filter funnel.

To have the cost of the washing of the filter cake as low as possible, we try to find a minimum volume of washing liquid, which will be enough for washing the desired amount of the substance. The amount of eluted substances is characterized by the degree of washing $y$.

When we search for the minimum volume we choose the appropriate soaking numbers $\mathrm{Na}$, when will be achieved the desired degree of washing, and subsequently we determine the optimal volume of the cost function. The volume corresponding to the minimum function is the searched optimal volume and the total costs corresponding to this minimum are the optimal cost, necessary to wash the desired amount of undesirable substance.

\section{Conclusion}

We carried out filtration and we washed several reaction mixes formed after the enzyme hydrolysis of chrome tanning parings and hydrolyzed bowels under defined conditions. With the help of existing mathematical models, we have expressed the specific resistances of filter cakes, which came into existence by filtration of the aforementioned suspensions. From the dependences of these resistances on developing under pressure, we set the compressible and incompressible cake and on the basis of these findings we have set the appropriate parameters of filtration.

On the basis of analyses of samples taken during the washing of the filter cake, we then determined the dependence of washout quality on the consumption of washout liquids for eluting the bound and unbound components. For eluting protein from the filter cake, we calculated optimal figure of washing liquid volume during which are minimal costs for washing required amount of undesirable component. Enzyme hydrolysis is environmentally friendly, during this process we fully uses chromium cake and high-quality protein hydrolysate.

In the next phase of our research, we will also focus on filter cake washing after enzymatic hydrolysis of other biowaste - for example, waste feathers to increase the yield of valuable protein.

\section{List of symbols}

Symbol Meaning

Unit

\begin{tabular}{|c|c|c|}
\hline$b$ & Half thickness of washed solid raw hide & [m] \\
\hline$c$ & Concentration of unbound component in solid phase & {$\left[\mathrm{kg} \cdot \mathrm{m}^{-3}\right]$} \\
\hline$C$ & Non-dimensional concentration field of washed component in solid phase & [1] \\
\hline$c_{0}$ & Concentration of component in washing bath & {$\left[\mathrm{kg} \cdot \mathrm{m}^{-3}\right]$} \\
\hline$C_{0}$ & Non-dimensional concentration of the component in bath & [1] \\
\hline$c_{p}$ & Initial concentration of component in solid phase & {$\left[\mathrm{kg} \cdot \mathrm{m}^{-3}\right]$} \\
\hline$c(t)$ & Concentration of salt that by diffusion goes into the soaking liquid & {$\left[\mathrm{kg} \cdot \mathrm{m}^{-3}\right]$} \\
\hline$c_{\infty}$ & Concentration of salt that by diffusion goes to soaking liquid in infinite time & {$\left[\mathrm{kg} \cdot \mathrm{m}^{-3}\right]$} \\
\hline$D$ & Effective value of diffusion coefficient & {$\left[\mathrm{m}^{2} \mathrm{~s}^{-1}\right]$} \\
\hline$\varepsilon$ & Porosity of solid phase & {$[1]$} \\
\hline$F_{0}$ & Non-dimensional time & {$[1]$} \\
\hline $\mathrm{Na}$ & Soak number, non-dimensional consumption of liquid & {$[1]$} \\
\hline$q_{n}$ & Roots of transcendental equation & {$[1]$} \\
\hline$S$ & Surface of raw hide & {$\left[\mathrm{m}^{2}\right]$} \\
\hline$t$ & Time & {$[\mathrm{s}]$} \\
\hline$V$ & Volume of the solid phase & {$\left[\mathrm{m}^{-3}\right]$} \\
\hline$V_{0}$ & Volume of the washing bath & {$\left[\mathrm{m}^{-3}\right]$} \\
\hline$x$ & Area coordinates & {$[\mathrm{m}]$} \\
\hline$X$ & Non-dimensional distance & {$[1]$} \\
\hline$y$ & Washing process stage & {$[1]$} \\
\hline
\end{tabular}




\section{Acknowledgements}

This work was supported by the Ministry of Education, Youth and Sports of the Czech Republic within the National Sustainability Programme Project No. LO1303 (MSMT-7778/2014) and also by the European Regional Development Fund under the project CEBIA-Tech No. CZ.1.05/2.1.00/03.0089

\section{References}

[1] Kolomazník, K. (1996). Recovery and recycling of chromium and protein from liquid and solid wastes from leather industry, ERB 3512 PL 940974 (COP 974).

[2] Janacova, D., Kolomaznik, K. \& Vasek, V. (2005). Optimization of liquids consumption at washing. 6th International Carpathian Control Conference. Miskolc-Lilafuered, Hungary, ISBN 963-661-644-2.

[3] Vasek, V., Kolomaznik, K. \& Janacova, D. (2006). Optimization and Automatic Control of Chromium Recycling Technology, WSEAS Transactions on Systems, 5 (11), ISSN 2651-2654.

[4] Sunaoka, Y., Kitazato, K., \& Tsuda, S. (1992). U.S. Patent No. 5,151,191. Washington, DC: U.S. Patent and Trademark Office.

[5] Tsubaki, Y., Kitajima, K., Hidetoshi, I., Hayashi, S., Ueda, A., Yagami, K., \& Yamada, S. (1991). U.S. Patent No. 5,050,259. Washington, DC: U.S. Patent and Trademark Office.

[6] Vasek, L. \& Dolinay V. (2010). International Journal of Mathematical Models and Methods in Applied Sciences, Vol. 4 (4), p. 240-248.

[7] Pitel, J., \& Mižák, J. (2013). Computational intelligence and low cost sensors in biomass combustion process. In Computational Intelligence in Control and Automation (CICA), 2013 IEEE Symposium on (pp. 181-184). IEEE.

[8] Božek, P. (2013). In Advances in Intelligent Systems and Computing: Proceedings of the International Conference on Systems Science, ICSS 2013; Wroclaw; Poland; p. 229-240. ISSN 2194-5357.

[9] Janacova, D., Kolomaznik, K., Mokrejs, P., Vašek, V. \& Líška, O. (2015). Optimization of one-stage extraction process. In Recent Advances in Systems. New Jersey, Piscataway: IEEE, p. 88-91. ISSN 1790-5117. ISBN 978-161804-321-4.

[10] Sambaer, W., Zatloukal, M., \& Kimmer, D. (2011). 3D modeling of filtration process via polyurethane nanofiber based nonwoven filters prepared by electrospinning process. Chemical Engineering Science, 66(4), 613-623. 